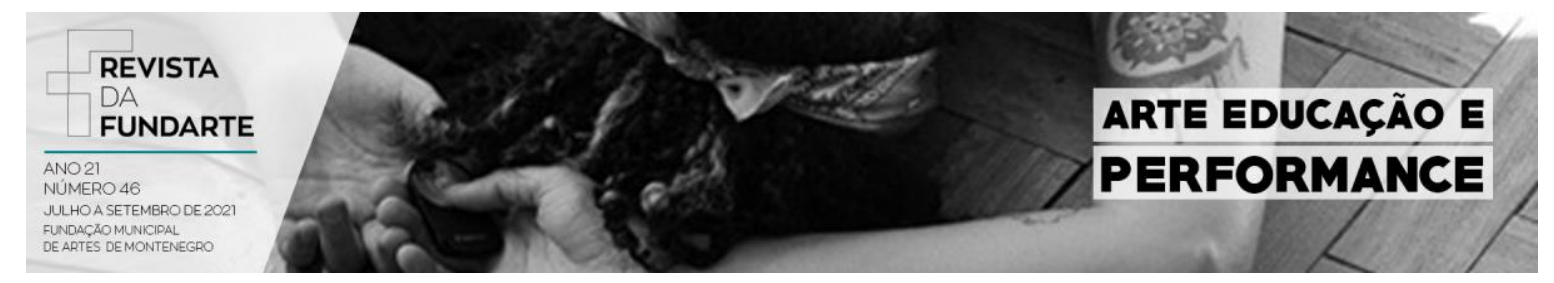

\title{
PULSAÇÕES: PROCESSO ENTRE CORPO, IMAGEM E SENSAÇÃO
}

\author{
Erico José Souza de Oliveira
}

DOI: http://dx.doi.org/10.19179\%2F2319-0868.827

OLIVEIRA, Erico José Souza de. PULSAÇÕES: processo entre corpo, imagem e sensação. Revista da FUNDARTE. Montenegro, p.01-18, ano 21, no 46, setembro de 2021.

Disponível em: http://seer.fundarte.rs.gov.br/index.php/RevistadaFundarte/issue/archive $>30$ de setembro de 2021. 


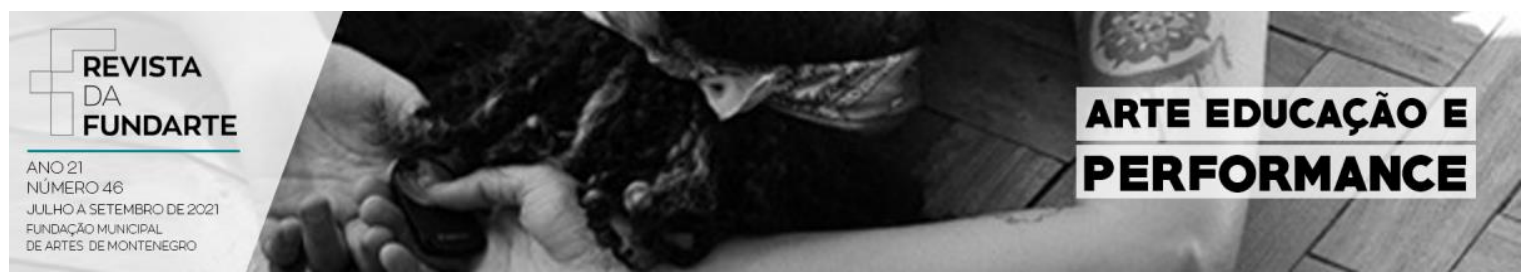

\title{
PULSAÇÕES: PROCESSO ENTRE CORPO, IMAGEM E SENSAÇÃO
}

\author{
Erico José Souza de Oliveira ${ }^{1}$
}

\begin{abstract}
Resumo: Este artigo socializa questões concernentes a elementos do processo de criação do espetáculo PULSAÇÕES, realizado em âmbito artístico-pedagógico do curso de interpretação teatral da Escola de Teatro da UFBA, em Salvador. A partir das noções de corpo, advindas das teorias de Georges Stobbaerts, Sônia Machado de Azevedo, Lenora Lobo e Cássia Navas, imagem e sensação, através das pesquisas de Denize Dall Bello, Adieliton Tavares Cézar, Helena Pinheiro JucáVasconcelos e Júnia César Pedroso, tal trabalho artístico abordou uma metodologia de preparação corporal aplicada aos ensaios do espetáculo, gerando possibilidades de encaminhamentos atorais e encenatórios que revelaram a potência do trabalho com imagens e sensações, desde o processo de montagem até a realização do espetáculo.
\end{abstract}

Palavras-chave: Corpo; imagem; sensação; emoção.

\section{PULSAÇÕES: PROCESS BETWEEN BODY, IMAGE AND SENSATION}

\begin{abstract}
This article socializes issues concerning the creative process' elements of theatrical piece PULSAÇÕES, carried out within an artistic-pedagogical approach on the Acting Major at the UFBA Theater School, in Salvador. From the notions of body arisen by the theories of Georges Stobbaerts, Sônia Machado de Azevedo, Lenora Lobo and Cássia Navas, image and sensation, through the researches of Denize Dall Bello, Adieliton Tavares Cézar, Helena Pinheiro Jucá-Vasconcelos and Júnia César Pedroso, such artistic work approached a methodology of preparing the body to acting applied to the play's rehearsals, generating possibilities of actor and stage directions that revealed the potency of the work with images and sensations, since the creation process until the performance itself.
\end{abstract}

Keywords: Body; Image; Sensation; emotion.

\footnotetext{
${ }^{1}$ Professor Dr. do Departamento de Artes Cênicas (CEN) e do Programa de Pós-Graduação em Artes Cênicas (PPG-CEN) da Universidade de Brasília (UnB). Professor colaborador do Programa de PósGraduação Interdisciplinar em Culturas Populares (PPGCULT), da Universidade Federal de Sergipe (UFS). Ator, encenador, iluminador, bailarino popular, produtor cultural, vice-líder do G-PEC (Grupo de Pesquisa em Processos, Poéticas e Pedagogias da Encenação Contemporânea), filiado ao CNPq.
}

OLIVEIRA, Erico José Souza de. PULSAÇÕES: processo entre corpo, imagem e sensação. Revista da FUNDARTE. Montenegro, p.01-18, ano 21, no 46, setembro de 2021.

Disponível em: http://seer.fundarte.rs.gov.br/index.php/RevistadaFundarte/issue/archive $>30$ de setembro de 2021. 


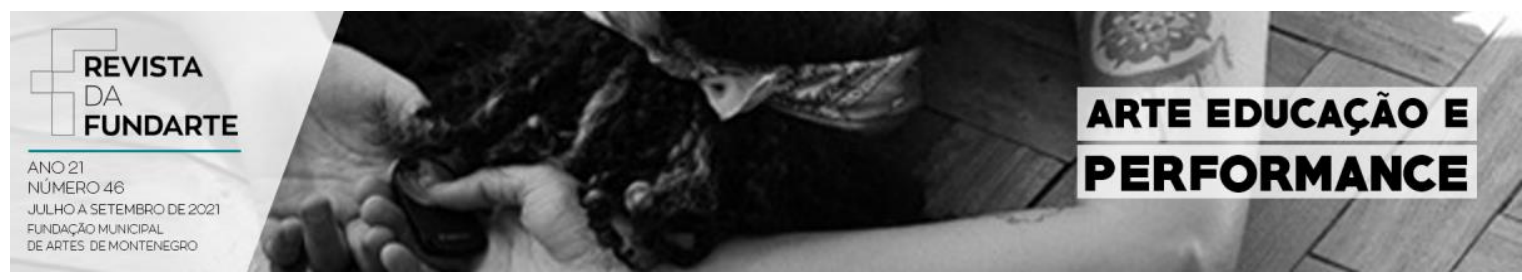

\section{Corpos sob véus clariceanos}

"E meu corpo irradiava-se em círculos de luz."

(Clarice Lispector)

Desvelar os véus das subjetividades ${ }^{2}$ existentes em um processo de criação cênica é algo que demanda direcionamentos em constantes mutações e trânsitos. Em se tratando de ter Clarice Lispector ${ }^{3}$ como uma das envolvidas no processo, tanto os véus quanto as subjetividades podem se multiplicar ao infinito, pois Clarice é, antes de tudo, imagem e sensação.

E plurais: imagens em movimento, sinuosas, penetrantes, imprecisas, turvas, nebulosas, inefáveis; sensações viscerais, complexas, ambivalentes, desconcertantes, paradoxais, indomáveis. E é este duo - imagem e sensação completamente atrelado a Lispector, o deflagrador do espetáculo intitulado PULSAÇÕES.

Porém, o processo de PULSAÇÕES começou sem título, sem imagem, sem sensação e sem Clarice. Tínhamos apenas nossos corpos ${ }^{4}$ no espaço. Corpos que já pulsavam na intenção de viver, sentir, partilhar algo, desvelar-se.

Por isso, antes de tratarmos de imagens e sensações, é preciso enfocarmos no lugar em que elas ressonam, ecoam e reverberam: no corpo. Georges

\footnotetext{
2 O professor e pesquisador Welington Andrade (2015, p. 278) trata da crise da subjetividade trazendo filosoficamente esta noção como a ideia de um sujeito significando "o eu", "a consciência" ou "a capacidade de iniciativa em geral": "assim é que a subjetividade entendida como o "caráter de todos os fenômenos psíquicos, porquanto fenômenos de consciência" (p. 1096-1099), pertencentes ao eu e ao sujeito do homem, irá interessar, a partir do século XIX, a todas as artes, de modo geral, impactando, de maneira bastante especial, a arte da cena."

${ }^{3}$ Nascida em Chechelnyk (Ucrânia), em 10 de dezembro de 1920, foi escritora, jornalista, romancista, contista. Sua obra é considerada um marco na literatura do século XX. Passou a infância no Recife e faleceu no Rio de Janeiro, em 9 de dezembro de 1977. Em 2020 se festeja 100 anos de seu nascimento. (https://pt.wikipedia.org/wiki/Clarice Lispector. Acesso em 17 de maio de 2020)

${ }^{4}$ Torna-se importante frisar que quando falamos em corpo, estamos abordando-o de forma orgânica, somática, na qual o aspecto sonoro estará sempre amalgamado em todas as atividades corporais.
}

OLIVEIRA, Erico José Souza de. PULSAÇÕES: processo entre corpo, imagem e sensação. Revista da FUNDARTE. Montenegro, p.01-18, ano 21, no 46, setembro de 2021.

Disponível em: http://seer.fundarte.rs.gov.br/index.php/RevistadaFundarte/issue/archive $>30$ de setembro de 2021. 


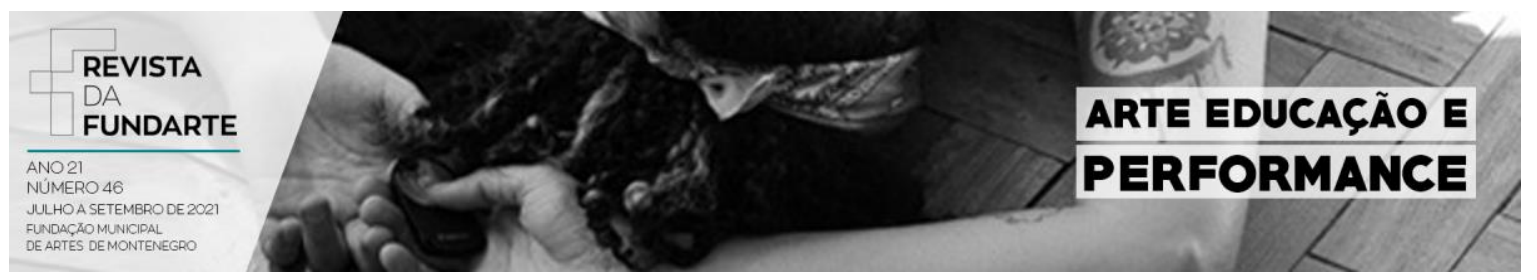

Stobbaertes (2014, p. 15) traz reflexões basilares sobre este mediador ${ }^{5}$ do acontecimento teatral ${ }^{6}$ :

Há muitas maneiras de se entender o termo corpo, o que levaria a pensar que existem muitos corpos: o corpo do lugar das nossas emoções, o corpo em oposição ao psiquismo, o corpo instrumento mecânico ou orgânico, o corpo em antítese com o espírito e assim por diante.

A crítica de Stobbaertes sobre os olhares esfacelados em relação ao corpo se contrapõe à sua visão do corpo sobre a cena como um todo orgânico que amalgama espaço interior (subjetivação) e espaço exterior (expressão): "Assim sendo, o corpo é o depositário da expressividade humana, meio privilegiado de realização do indivíduo." (STOBBAERTS, 2014, p. 15).

Lenora Lobo e Cássia Navas (2003, p. 79) dialogam com Stobbaerts ao sinalizar que "[...] o corpo é onde tudo começa e termina, onde tudo se traduz e se manifesta, o centro do estudo primeiro do ator-bailarino. O corpo, habitação da nossa existência, tão simples e tão complexo, parece guardar dentro de nós toda a sabedoria do universo."

Clarice Lispector (1999, p. 20), a todo momento de sua escrita, vincula imagens e sensações ao corpo:

Senti a pulsação da veia em meu pescoço, senti o pulso e o bater do coração e de repente reconheci que tinha um corpo. Pela primeira vez da matéria surgiu a alma. Era a primeira vez que eu era una. Una e grata. Eu me possuía. O espírito possuía o corpo, o corpo latejava ao espírito.

\footnotetext{
${ }^{5}$ A noção de mediador é cara a Denize Dall Bello e será exposta a seguir. Júnia César Pedroso (2007, p. 04) também faz uso dessa expressão: "O corpo é o mediador desta presença do artista no reino do possível, situando-se num tempo-espaço construído, em que experiência cria sentidos para um outro que o observa."

${ }^{6}$ Aqui usamos o termo cunhado por Jorge Dubatti, no qual o acontecimento é um fenômeno que acontece a partir de três condições: 1 - convívio (reunião de corpos presentes); 2 - poiésis (o corpo como metáfora, criação imagética no espaço); 3 - expectação (zona de contato entre quem executa a poiésis e quem a contempla): "(...) o que não pode faltar no acontecimento teatral: a reunião dos corpos viventes produzindo poiésis em convívio, onde haja geração corporal de poiésis e expectação." (ROMAGNOLLI, Luciana Eastwood; MUNIZ, Mariana de Lima, 2014, p. 255)
}

OLIVEIRA, Erico José Souza de. PULSAÇÕES: processo entre corpo, imagem e sensação. Revista da FUNDARTE. Montenegro, p.01-18, ano 21, no 46, setembro de 2021.

Disponível em: http://seer.fundarte.rs.gov.br/index.php/RevistadaFundarte/issue/archive $>30$ de setembro de 2021 . 


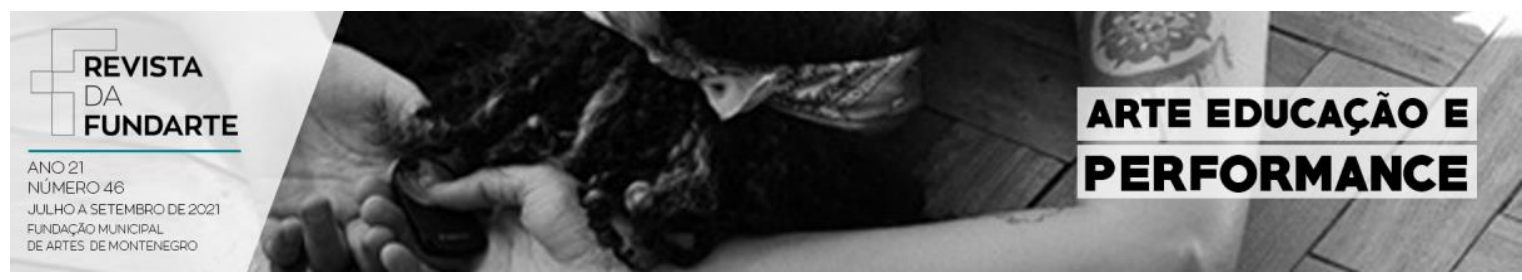

Esse corpo que absorve e refrata subjetividades, imagens, sensações, vivências íntimas e sociais que ficam encrustadas na musculatura, na psiquê e na memória, é o vórtice fundante desta experiência cênica.

O que interliga Stobbaerts, Lobo e Navas ao processo de PULSAÇÕES são as estreitas relações entre práticas artístico-pedagógicas tendo o corpo como vetor do processo cênico, com a atenção voltada para a relação entre as subjetividades dos/as artistas e as possibilidades que os corpos carregam enquanto corpo em signo $^{7}$ na cena, através da construção de imagens e sensações.

E como nos alerta Sônia Machado de Azevedo (2004, p. 142), o nível de mergulho neste universo que é o corpo é sempre um processo de auto educação, no qual "[...] a aprendizagem, por melhor que seja conduzida, é um processo solitário."

Assim como Lispector, o autor e as autoras acima aspiram uma fusão entre corpo e espírito, um equilíbrio - mesmo que transitório e precário - na balança de afetos, relações, imagens e sensações. $E$ foi por isso que Clarice Lispector se incorporou ao processo ainda sem nome e que viria a se intitular PULSAÇÕES, subtítulo de sua obra Um sopro de vida, que inspirou o espetáculo.

Com nossos corpos e o livro de Lispector, tornou-se necessário pensar o processo através de imagens $^{8}$, isto é, desenvolver uma abordagem sensível e imagética sobre a obra, mudando a tendência de mirada academicista/tecnicista, na

\footnotetext{
7 Sônia Machado de Azevedo (2004, p. 147), traz a ideia de corpo em signo no trabalho autoral, no momento em que os/as artistas da cena entram na fase expressivo-estética, na qual a relação entre subjetividade, imaginário e expressão se coadunam na tessitura de um corpo-imagem: "A forma dada à expressão será mais do que nunca privilegiada, sem esquecer, no entanto, das experiências vividas ou imaginadas que possam servir de recurso pessoal na criação do signo." Esta ideia de signo reverbera a noção de poiésis de Dubatti (2014).

8 Aqui, trazemos o entendimento de imagem como percepção mental sobre alguém ou algo ou alguma forma; impressão de um objeto no espírito; aquilo que simbólica ou realmente imita, personifica ou representa pessoa ou coisa; reprodução na mente de uma sensação ou percepção anteriormente vivida ou sentida; imagem completa armazenada em memória, e não apenas a parte que é mostrada. Ver: MICHAELIS. Moderno dicionário da língua portuguesa. São Paulo: Companhia Melhoramentos, 1998, p.1128. Ou https://michaelis.uol.com.br/moderno-portugues/busca/portuguesbrasileiro/imagem/. Acesso em 17 de maio de 2020.
}

OLIVEIRA, Erico José Souza de. PULSAÇÕES: processo entre corpo, imagem e sensação. Revista da FUNDARTE. Montenegro, p.01-18, ano 21, no 46, setembro de 2021.

Disponível em: http://seer.fundarte.rs.gov.br/index.php/RevistadaFundarte/issue/archive $>30$ de setembro de 2021. 


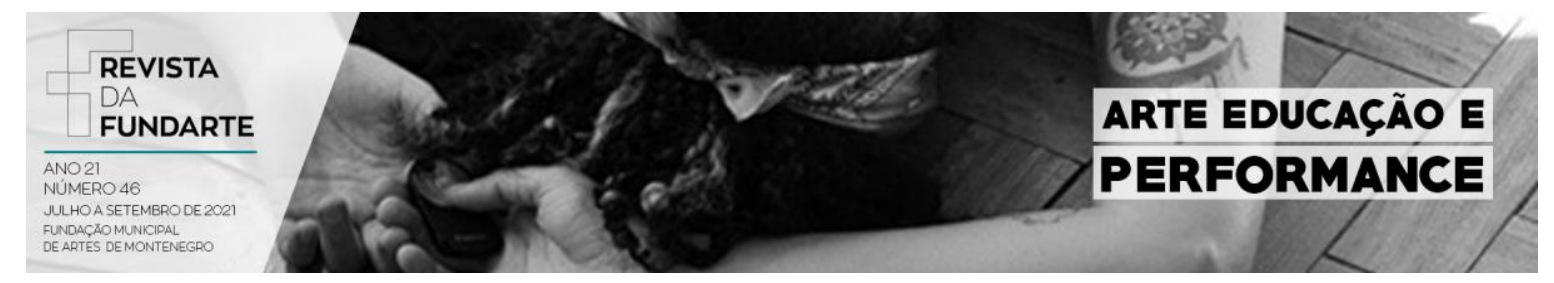

qual o texto enquanto discurso escrito/lógico - e falado - é visto como a forma mais eficaz de se relacionar com a cena, de significar.

$\mathrm{E}$, das imagens provindas da nossa relação com Clarice Lispector, pudemos mergulhar nas mais diversas sensações que Um sopro de vida nos imprimia, tendo o corpo como o deflagrador desse trânsito entre o interno (o íntimo e subjetivo) e o externo (a relação e a expressão), atentos/as aos véus que se descortinavam perante nossos olhos e nossos corpos.

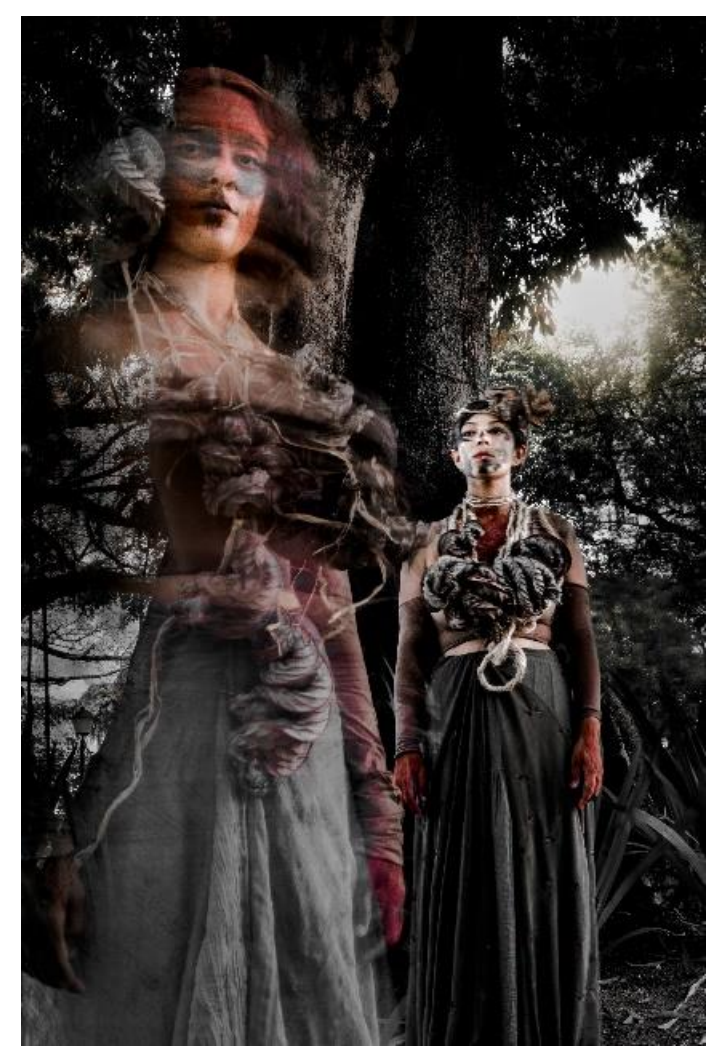

Giovanna Boliveira e Rebeca de Oliveira Em experimento ao ar livre

(Passeio Público - Salvador- agosto/2019)

Foto: Gustoyle

OLIVEIRA, Erico José Souza de. PULSAÇÕES: processo entre corpo, imagem e sensação. Revista da FUNDARTE. Montenegro, p.01-18, ano 21, no 46, setembro de 2021.

Disponível em: http://seer.fundarte.rs.gov.br/index.php/RevistadaFundarte/issue/archive $>30$ de setembro de 2021. 


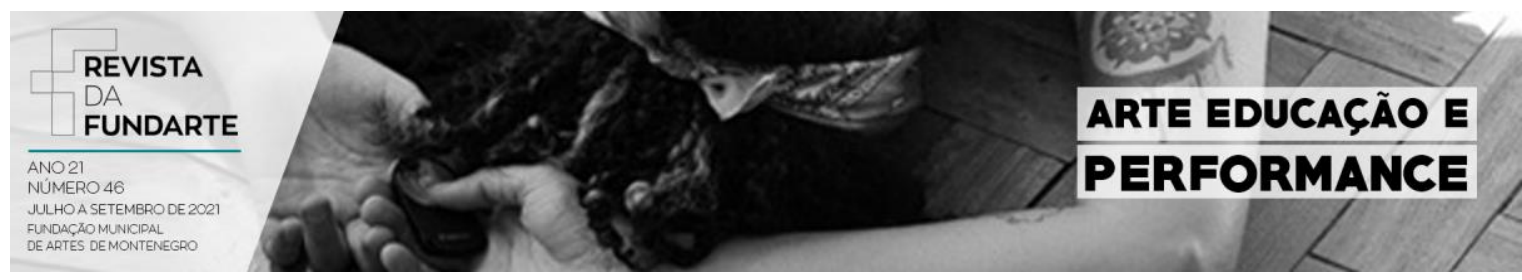

Pulsando emoções, imagens e sensações

"A imaginação antecede a realidade!"

(Clarice Lispector)

Iniciamos esta seção trazendo uma diferenciação entre sensação e emoção ${ }^{9}$, pois que a emoção, segundo Denize Dall Bello (2016) é um atributo da recepção, isto é, da relação entre espectador/a e obra de arte. Aqui, enfocamos nossa reflexão sobre a relação do/a artista com sua criação, isto é, ele/a enquanto agente e obra cênica, ao mesmo tempo.

A discussão sobre o uso ou não da emoção no trabalho dos/as artistas da cena é muito antiga e não caberá desenvolvê-la neste artigo, mas podemos situá-la como um recorte possível de Denis Diderot e seu Paradoxo sobre o Comediante até os dias atuais, passando inevitavelmente por Constantin Stanislavski e Vsevolod Meierhold, entre muitos/as outros/as, a partir de suas pesquisas sobre a atuação.

Nesta compreensão sobre a importância das sensações para o trabalho da atuação cênica e da emoção enquanto atributo do/a espectador/a, Júnia César Pedroso (2007, p. 01), contribui para referendar nossa perspectiva:

A percepção dos sentidos orgânicos gera sensações, que provocam uma cadeia de emoções, ainda indiferenciadas, que são elaboradas sob a forma de sentimentos, que podem ser nomeados: amor, ódio etc. As sensações são mais visíveis, através do tônus muscular e das expressões do comportamento humano, e portanto, decodificáveis, enquanto os sentimentos/emoções apenas podem ser deduzidos hipoteticamente pelo espectador."

\footnotetext{
9 Para que possamos fugir do senso comum sobre a noção de emoção, eis uma definição de Adieliton Tavares Cezar e Helena Pinheiro Jucá-Vasconcelos 2016, p. 07): "De acordo com Bock, Furtado e Teixeira (2008), as emoções são expressões de afeto acompanhadas de reações intensas e breves do organismo em resposta a um acontecimento inesperado ou, às vezes, muito aguardado, fantasiado. Nas emoções é possível observar a relação entre os afetos e a expressão corporal. As reações orgânicas presentes na emoção fogem ao controle do indivíduo. [...] Eles ainda expõem que todas as reações orgânicas relativas à emoção são importantes descargas de tensão. Portanto, de acordo com esses autores, a emoção é um momento de tensão em um organismo, e as reações orgânicas são descargas emocionais."
}

OLIVEIRA, Erico José Souza de. PULSAÇÕES: processo entre corpo, imagem e sensação. Revista da FUNDARTE. Montenegro, p.01-18, ano 21, no 46, setembro de 2021.

Disponível em: http://seer.fundarte.rs.gov.br/index.php/RevistadaFundarte/issue/archive $>30$ de setembro de 2021. 


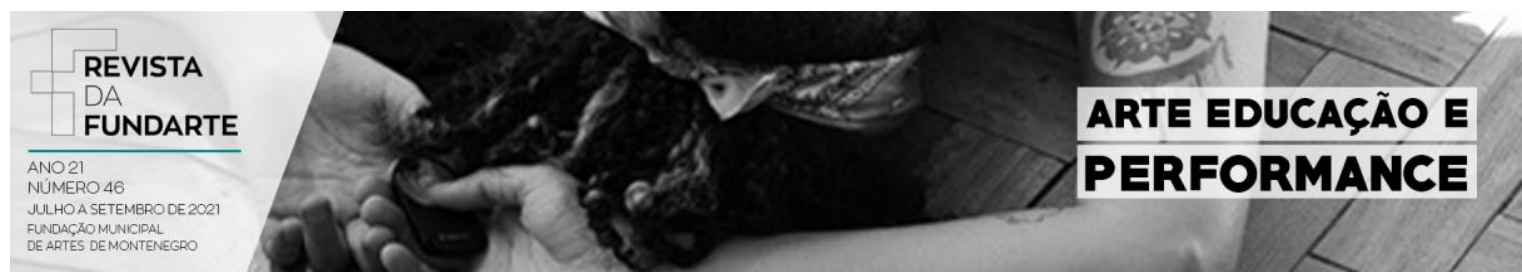

No processo de PULSAÇÕES, trabalhamos com a noção de sensação, pois acreditamos que cabe ao público, através de seu contato com a obra, se relacionar com ela pelo viés das emoções. Aos/Às artistas da cena, no nosso ponto de vista, cabe o trabalho com as imagens e as sensações para provocar no/a espectador/a emanações energéticas que se transformarão em emoções, através das subjetividades de cada pessoa.

Devido a este tema tão complexo e contraditório, veremos como se dá esta relação entre a obra de arte e a emoção, para, em seguida, retomarmos a discussão sobre o duo imagem e sensação trabalhado em PULSAÇÕES, pois tanto as emoções quanto as sensações se pronunciam através do corpo.

Denize Dall Bello (2016) discute de forma bastante aprofundada as relações entre imagem, emoção e corpo, através de campos distintos do conhecimento, como a neurociência (Antonio Damásio) e a história da arte (Aby Warburg), revelando que as imagens - independentemente de quais sejam e de quais fontes as concretizam - não são criadas para serem contempladas, mas para nos atravessar, para criar um vínculo direto, o qual passam a fazer parte de nosso corpo.

É através da relação dos corpos com as imagens que as emoções se produzem por um processo de empatia ${ }^{10}$, responsável pela seleção e organização cerebral do que a memória reterá como via de mão dupla entre corpo/mente imagem/emoção: "Tornar-se-ão imagens, somente aquelas em que nós projetamos emoções. A hipótese de Damásio é que a emoção é a raiz da consciência. Por essa razão, quando a emoção nos invade é que nós tomamos consciência do corpo." (BELLO, 2016, p. 20)

\footnotetext{
10 Denize Dall Bello (2016, p. 46-47) localiza a raiz neurológica da empatia nos neurônios espelhos e a relacionada a processos de imitação e de projeção sobre algo ou sobre o/a outro/a: "A empatia nos liga à situação do outro. Ligar quer dizer criar vínculo. Portanto, a capacidade da empatia tem a ver com o desenvolvimento de um "pulmão" capaz de maior abertura para novos ares, de mais ligações. $\mathrm{Na}$ verdade, essa habilidade exige um corpo, uma cabeça, um coração, uma pele capaz de assimilar porosamente nosso meio ambiente (Contrera, 2012:189).
}

OLIVEIRA, Erico José Souza de. PULSAÇÕES: processo entre corpo, imagem e sensação. Revista da FUNDARTE. Montenegro, p.01-18, ano 21, no 46, setembro de 2021.

Disponível em: http://seer.fundarte.rs.gov.br/index.php/RevistadaFundarte/issue/archive $>30$ de setembro de 2021 . 


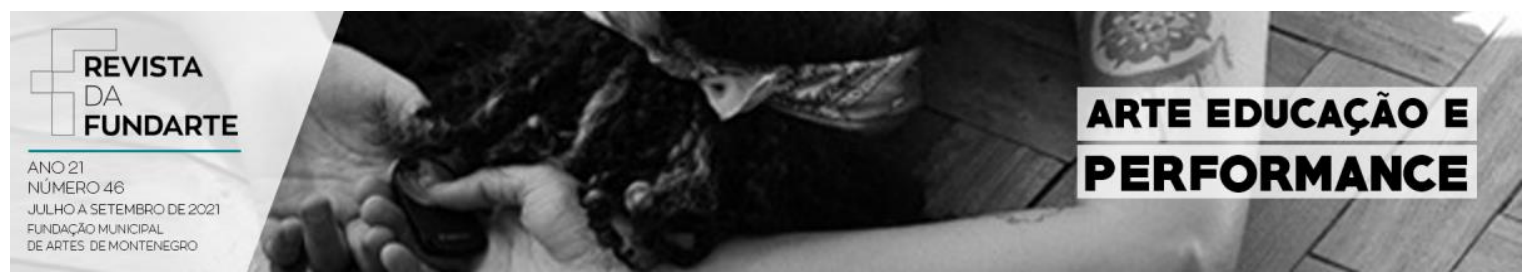

Bello localiza neste duo - imagem e emoção - a potência dos acontecimentos cênicos, tendo o corpo como mediador vivo que incorpora, seleciona e externa nossa relação entre imagem, memória e emoção, pois "[...] não há como deixar de olhar o corpo, o nosso mediador vivo. Ele recebe, produz, armazena e comunica nossos estados internos." (BELLO, 2016, p. 62)

Para Bello, toda imagem é um receptáculo de emoções, que só ressoa em nós pela relação que se dá entre ela e nossa experiência de mundo, gerando expectativas e projeções, estimulando nossa imaginação. As imagens projetadas diante de nós passam a se configurar como incompletas em si mesmas, como borrões, precisando de nossa empatia para que se amalgamem ao nosso corpo, e isto faz com que a imagem seja captada de formas diferentes por cada indivíduo, a partir de suas singularidades, subjetividades e vivências:

Porque o divertido não é chegarmos a um acordo sobre a imagem vista. $\mathrm{O}$ divertido é percebermos a nossa capacidade de imaginação acontecendo. A partir desses borrões nós evocamos figuras que conhecemos ou imaginamos. Na projeção vale quase tudo. Como dissemos, a preocupação sobre como chegar a um resultado universal, a uma imagem comum é o que menos importa. (BELLO, p. 67).

Adieliton Tavares Cézar e Helena Pinheiro Jucá-Vasconcelos (2016, p. 08) nos presenteia com uma explicação sobre esse fluxo pessoal e intransferível que emana da complexa simbiose entre corpo e imagem, isto é, as emoções, que são multidimensionais e envolvem fenômenos subjetivos, biológicos e sociais:

Scherer (2005) aponta a existência de cinco componentes para que haja um
estado emocional: cognição, sintomas físicos (componentes neurológicos),
motivação, expressão motora e experiência subjetiva ou sentimento. O
componente cognitivo da emoção avalia os objetos e eventos que se
manifestam no mundo externo. O componente neurofisiológico surge para a
regulação do organismo. A função do componente motivacional é preparar e
direcionar ações. A expressão motora manifesta a reação e sua intenção
correspondente. A experiência subjetiva monitora o estado do organismo
frente à sua interação com os eventos e objetos.

OLIVEIRA, Erico José Souza de. PULSAÇÕES: processo entre corpo, imagem e sensação. Revista da FUNDARTE. Montenegro, p.01-18, ano 21, oㅜ 46, setembro de 2021.

Disponível em: http://seer.fundarte.rs.gov.br/index.php/RevistadaFundarte/issue/archive $>30$ de setembro de 2021. 


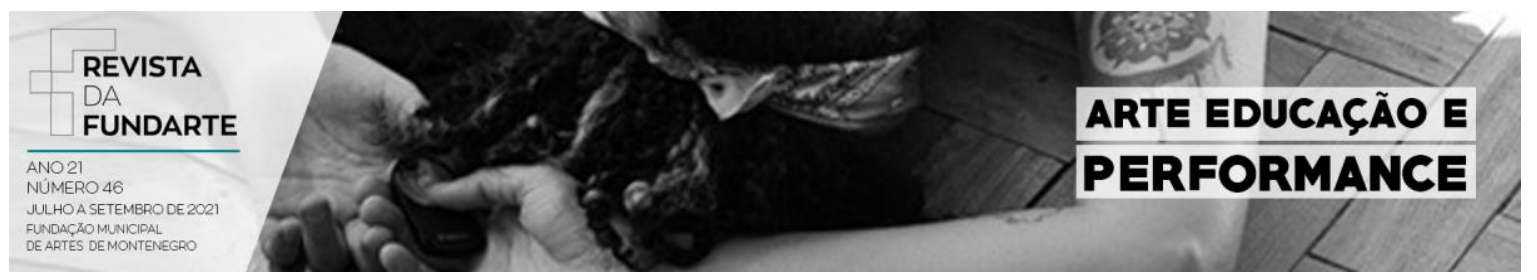

Através de seus personagens, auto-imagens da autora, Clarice Lispector (1999, p. 46) nos brinda com esta percepção sobre sua escritura poética, na qual as imagens são gestantes e gestoras das emoções, sensações, imaginações e criações:

O processo que Ângela tem de escrever é o mesmo processo do ato de sonhar: vão-se formando imagens, cores, atos, e sobretudo uma atmosfera de sonho que parece uma cor e não uma palavra. Ela não sabe explicar-se. Ela só sabe é mesmo fazer e fazer sem se entender.

O processo de PULSAÇÕES ${ }^{11}$ começou, como dito acima, através de um trabalho corporal tendo as relações do corpo no espaço como deflagradoras de possibilidades cênicas, a partir de um trabalho de consciência corporal na busca do que chamamos de elementos imateriais da cena ${ }^{12}$.

Nas atividades que direcionavam essa proposta, os corpos das atrizes já se tornavam, por si, imagens que inundavam o espaço da sala de ensaio de sensações cinestésicas. A intenção sempre foi de que a percepção aguda da respiração junto à cadeia muscular, através de uma consciência rítmica, plástica, energética e sonora do corpo no espaço, promovesse nas atrizes projeções de imagens e sensações do interior (os corpos) para o exterior (o espaço) e vice-versa.

\footnotetext{
11 Aqui não iremos nos ater à narrativa esmiuçada de exercícios utilizados no processo de PULSAÇÕES, mas às questões que nortearam a pesquisa corporal. Portanto, alguns indícios de trabalhos cênico-pedagógicos serão trazidos à baila somente quando for essencial ao entendimento das questões suscitadas.

${ }^{12}$ Considera-se, aqui, como elementos imateriais da cena, as construções de atmosfera, energia, tempo-ritmo, temperatura e temperamento aplicadas tanto ao trabalho de encenação como de atuação, a partir de imagens apreendidas da dramaturgia estudada ou de textos conexos, sejam teóricos, artísticos, etc. Neste caso, tal procedimento antecede o pensamento dos elementos materiais da cena, a saber, cenografia, figurino, objetos, iluminação, etc. Para aprofundamento sobre elementos imateriais, ver: OLIVEIRA, Erico José Souza de; LíRIO, Vinícius da Silva. Teatralidades híbridas y elementos inmateriales en Esta propiedad está condenada de Tennessee Williams. Cuadernos de Música, Artes Visuales y Artes Escénicas, Bogotá, Vol. 10, N. 1, enero-jun. de 2015, pp. 153-165.
}

OLIVEIRA, Erico José Souza de. PULSAÇÕES: processo entre corpo, imagem e sensação. Revista da FUNDARTE. Montenegro, p.01-18, ano 21, no 46, setembro de 2021.

Disponível em: http://seer.fundarte.rs.gov.br/index.php/RevistadaFundarte/issue/archive $>30$ de setembro de 2021. 


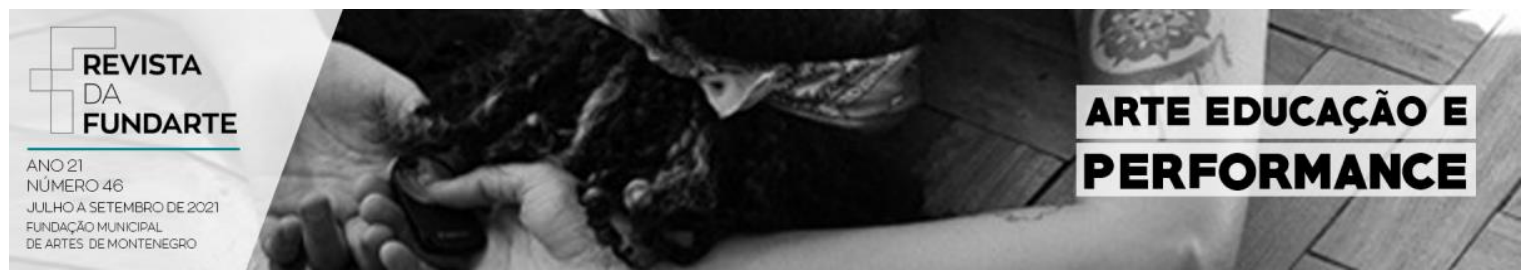

A partir daqui, torna-se necessário fundamentar a noção de sensação, para que sigamos o fluxo das experimentações em PULSAÇÕES. Voltando a CÈZAR e JUCÁ-VASCONCELOS (2016, p. 06), eis uma definição inicial sobre sensação:

As sensações podem ser definidas como a impressão causada em um órgão receptor através de um estímulo (interno ou externo). Portanto, a sensação é um fenômeno puramente perceptual, basicamente uma atividade dos sentidos. (RIES, 2004; REEVE, 2006).

Tratando da Gestalt-terapia, a autora e o autor entendem que o mergulho nas sensações é a base para "[...] uma tomada de consciência plena no momento presente. É um processo de compreender, de reunir partes separadas em um todo significante. É uma atenção ao conjunto de percepção pessoal, corporal, emocional, interior e exterior." (CÉZAR, JUCÁ-VASCONCELOS, 2016, p. 09)

Segundo a autora e o autor, as sensações, na Gestalt-terapia, visam o trabalho com a awareness, que é um processo contínuo e aberto de autoconsciência:

Fukumitsu (2012) entende a awareness como uma capacidade de integração entre o que o indivíduo faz e como faz. A autora aponta ainda que este processo envolve três zonas denominadas zonas de awareness, sendo elas: Awareness do mundo exterior: todos os contatos estabelecidos por meio das funções de contato. Awareness do mundo interior: respiração, sensações, sentimentos, emoções, percepções da tensão, relaxamento, postura. Awareness da atividade da fantasia: todas as atividades mentais - pensamento, imaginação, projetos etc. (FUKUMITSU, 2012, p.70). (CÉZAR e JUCÁ-VASCONCELOS, 2019, p. 09. Grifos da autora e do autor)

Este processo de tomada de consciência - awareness - tem seu núcleo na percepção das sensações e "[...] ocorre quando há uma relação entre os níveis cognitivos, sensoriais, motores, emocionais e energéticos. Com isso o indivíduo

OLIVEIRA, Erico José Souza de. PULSAÇÕES: processo entre corpo, imagem e sensação. Revista da FUNDARTE. Montenegro, p.01-18, ano 21, no 46, setembro de 2021.

Disponível em: http://seer.fundarte.rs.gov.br/index.php/RevistadaFundarte/issue/archive $>30$ de setembro de 2021. 


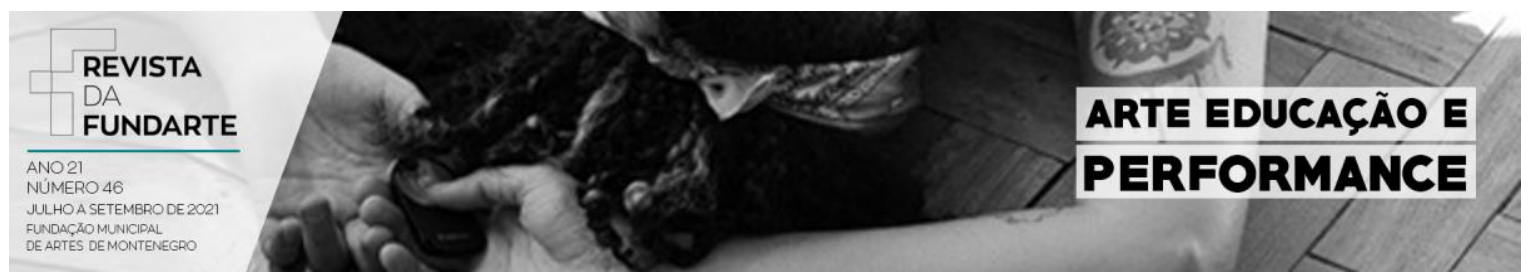

passa a ter uma percepção clara daquilo que ele experiência (FUKUMITSU, 2012)." (CÉZAR e JUCÁ-VASCONCELOS, 2016, p. 09)

Estes procedimentos reverberam nas práticas artístico-pedagógicas de STOBBAERTS (2014, p. 16): "O trabalho sobre o corpo passa por uma consciência, mas esta deve ser também um lugar de revelação do ser." Da mesma forma, no sentido da auto-educação dos processos aconselhados por Sônia Machado de Azevedo (2004, p. 135):

$\mathrm{O}$ ator deve ser aquele que entra diretamente em contato com o fenômeno da expressão, percebendo como, quando e por que ela ocorre em si mesmo. Deve aprender a ver-se, trabalhar seu corpo e partes deste como um artista ao misturar as cores, observando o efeito, preparando um quadro.

Em PULSAÇÕES, as percepções internas do corpo (órgãos, musculatura, ossatura, sistema nervoso, sistema circulatório, sistema respiratório, chacras, etc.) e externas (peso, posturas, tensões, torções, travamentos físicos, esforço, extensão, contração, vetores, etc.) encaminhavam as atrizes para uma consciência sensóriocorporal, fazendo com que as sensações surgidas no processo as movimentassem no espaço.

Neste caso, os estímulos iniciais dos experimentos com o corpo eram as imagens internas, produzidas pelos movimentos corporais e pelas sensações e, em derivação, os corpos transubstanciavam-se em imagens e sons em deslocamento espacial.

A experimentação com os estímulos imagéticos externos veio um pouco mais tarde, a partir de Um sopro de vida, de Clarice Lispector: a atividade central na relação com o texto consistia em ler o livro deixando fluir do universo da autora,

OLIVEIRA, Erico José Souza de. PULSAÇÕES: processo entre corpo, imagem e sensação. Revista da FUNDARTE. Montenegro, p.01-18, ano 21, no 46, setembro de 2021.

Disponível em: http://seer.fundarte.rs.gov.br/index.php/RevistadaFundarte/issue/archive $>30$ de setembro de 2021. 


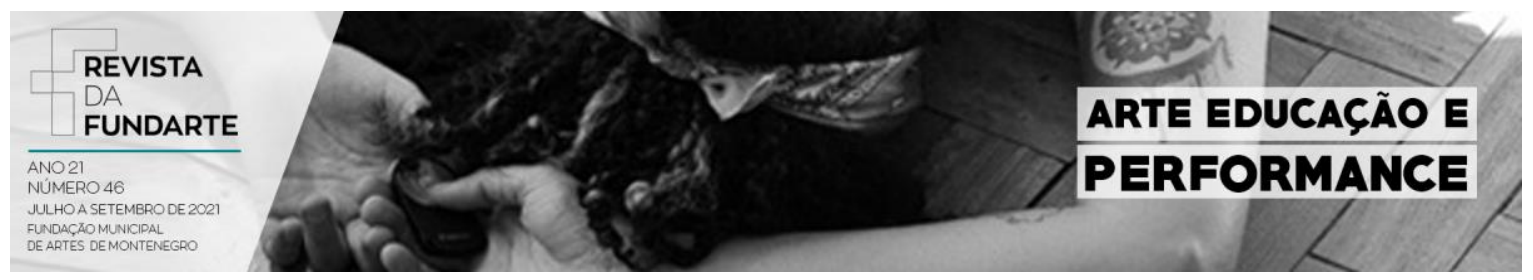

imagens emblemáticas ${ }^{13}$ que seriam anotadas e trabalhadas corporalmente em sala de ensaio.

Cada participante do processo (atrizes/encenadoras, diretora de arte, preparadora corporal, preparadora vocal, iluminador/encenador, etc.), à medida em que lia o livro, criava estratégias para estabelecer uma relação sensorial com ele, dirimindo a tendência racionalista de relação puramente cognitiva com uma obra literária. A busca era experimentar se relacionar com as palavras por imagens e sensações em consonância com o próprio corpo, pois, como nos diz Bello (2016, p. 15) "[...] no princípio é o corpo quem está na origem da comunicação como de fato nos faz perceber que a raiz do teatro está no mundo sensorial."

Selecionadas as imagens emblemáticas, a cada ensaio, elas se tornavam o estímulo para que as atrizes acessassem suas sensações e imagens pessoais e as transformassem em corpo em movimento. O mundo imagético lispectoriano passava pelo mundo interno das atrizes e desembocava em imagens corporais prenhes de sensações e sonoridades, aprofundando a percepção dos elementos imateriais da cena, seja individual ou coletivamente.

Outra atividade voltada para esta relação texto-imagem-sensação foram as leituras de visualização e peso das palavras: através da escolha de palavras isoladas do texto, sob uma técnica de respiração específica, a palavra escolhida é degustada e introjetada para, em seguida, ser transformada em imagem e sensação e, por fim, ser falada com todas as construções internas experimentadas nesse processo. ${ }^{14}$

13 Tratamos como imagens emblemáticas a imagens provindas desta relação sensorial com o texto e
que, não necessariamente, estão explícitas na escrita. A relação se dá em um nível não
lógico/racional, no qual as imagens emblemáticas podem parecer desconectadas do universo da obra
lida, mas serão fundamentais tanto para o encaminhamento processual do espetáculo, quanto para
seu resultado, encaminhando questões como atmosferas, sensações, ritmos, energias, etc.
(elementos imateriais da cena) e a visualidade do espetáculo (elementos materiais da cena). Para
aprofundamento sobre imagens emblemáticas, ver: OLIVEIRA, Erico José Souza de; LíRIO, Vinícius
da Silva (2015).
14 Este trabalho de texto-imagem-sensação foi aplicado em 1995, na oficina Acting Workshop'95,
ministrada pelo ator Ricardo Barretto (vindo à época de sua formação no Actor's Studios, nos EUA),

OLIVEIRA, Erico José Souza de. PULSAÇÕES: processo entre corpo, imagem e sensação. Revista da FUNDARTE. Montenegro, p.01-18, ano 21, no 46, setembro de 2021.

Disponível em: http://seer.fundarte.rs.gov.br/index.php/RevistadaFundarte/issue/archive $>30$ de setembro de 2021. 


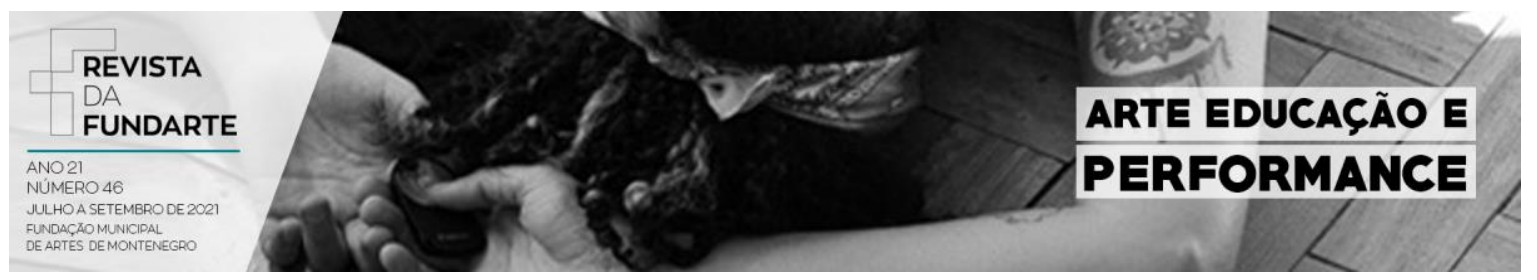

A partir dessas experimentações, começamos a selecionar quais seriam as imagens emblemáticas que poderiam ser as norteadoras de temas e das ideias principais de montagem do espetáculo. Desde o primeiro contato com Um sopro de vida, havia uma imagem muito forte que pairava na equipe: a imagem de véus.

Tais véus escondiam espaços distintos, formas diversas e seres improváveis que se desvelavam a cada momento. A imagem dos véus nos chegou como possibilidades de construções cênicas variadas e independentes entre si, como se a cada desvelamento, um universo fosse desnudado, um outro mundo surgisse, um outro espetáculo brotasse diante do público. Este mecanismo-sonho foi a chave da proposta de encenação que nos libertou de perseguir os caminhos da lógica, racionalidade, coerência, causalidade e temporalidade cênicas.

Estes encaminhamentos também impulsionaram o processo de encenação e de atuação de PULSAÇÕES para a desconstrução da ideia convencional de personagem. Ao invés disto, começamos a produzir quadros, composições corporais, células cênicas que possuíam em si sua significância. No lugar da ideia de personagem, por trás dos véus, surgiam imagens, criaturas, seres. Essas criações atorais foram nomeadas de "figuras". 15

Nestas veredas recorremos a várias possibilidades investigativas, passando por bufonaria, palhaçaria, realismo, teatro épico, teatro narrativo, teatro biográfico, performance, instalação, dança, práticas culturais, entre outras.

Porém, o interesse não era utilizar essas possibilidades estéticas de forma a reproduzi-las como espelho dentro do espetáculo, mas como estímulos para que daí

promovida pelo Departamento de Teoria da Arte e Expressão Artística da UFPE, para os alunos da Licenciatura em Educação Artística (nome do curso na época). Jaques Lecoq também trabalhou com técnicas similares nas quais enfatizava a relação das palavras com imagens, visualizações e peso. Ver: https://www.youtube.com/watch?v=koExYifgFRo. Acesso em 17 de maio de 2020.

${ }^{15} \mathrm{~A}$ escolha deste termo é uma alusão direta às epistemologias contidas na prática cultural do Cavalo Marinho da Zona da Mata Norte de Pernambuco. Não à toa, optamos por criar um trânsito entre ela e nossa prática cênica, porém, este recorte de pesquisa não cabe no escopo deste artigo. Para aprofundar a noção de figura no universo do Cavalo Marinho pernambucano, ver: OLIVEIRA, Erico José Souza de Oliveira. A roda do mundo gira: um olhar sobre a brincadeira do Cavalo Marinho Estrela de Ouro (Condado-PE). Recife: SESC, 2006.

OLIVEIRA, Erico José Souza de. PULSAÇÕES: processo entre corpo, imagem e sensação. Revista da FUNDARTE. Montenegro, p.01-18, ano 21, no 46, setembro de 2021.

Disponível em: http://seer.fundarte.rs.gov.br/index.php/RevistadaFundarte/issue/archive $>30$ de setembro de 2021. 


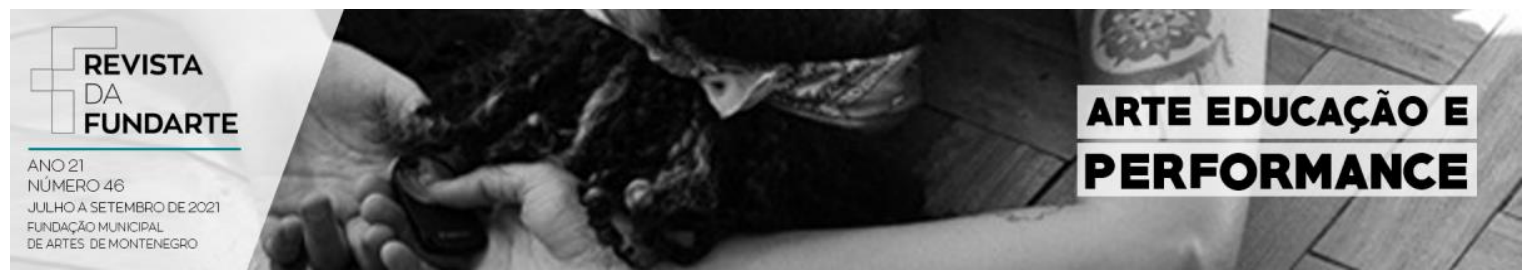

surgissem outros meios de expressão que tivessem vida cênica em si mesmos, como um mosaico de imagens em movimento.

Esta liberdade contida neste processo de criação provindo das inesgotáveis relações entre corpos, imagens e sensações foi o mote necessário para que não nos prendêssemos a estilos de interpretação, gêneros teatrais ou estéticas cênicas específicas. Também nos deu a oportunidade de não tratar o livro de Clarice Lispector como uma adaptação ou uma versão para a cena, mas como um mobilizador de questões pessoais e sociais, retrabalhadas a partir de temas de interesse das atrizes, como o feminino, o lugar da mulher na sociedade e na arte, o teatro como elemento de convívio e reflexão social, etc.

Enfocamos no que denominamos de composições cênicas, isto é, universos independentes de significação, como se fossem ambientes oníricos que os véus lispectorianos descortinavam perante os olhos dos/as espectadores/as, os conclamando a construir juntos/as, a partir das imagens, sensações e emoções que seus corpos reverberavam.

Assim como a relação que Lispector estabelece com as palavras, ora metáforas de um mundo interior, ora crítica sociocultural, ora barreiras para revelar o que se sente, PULSAÇÕES absorveu este pensamento à medida em que as palavras, no espetáculo, iam aos poucos perdendo espaço para as imagens que inundavam a cena.

$E$ as sensações que emanavam do espetáculo foram belamente expressas pelas palavras-cores de Clarice Lispector (1999, p. 51),

O que está me sucedendo é a Graça? Porque o corpo eu não o sinto, ele não me pesa, nem deseja, o espírito não se contorce e não busca, envolveme uma aura luminosa de silêncio: pairo no ar, livre do tempo mas plenamente neste próprio instante, sem antes nem depois. Me recebo e o mundo não me toca.

OLIVEIRA, Erico José Souza de. PULSAÇÕES: processo entre corpo, imagem e sensação. Revista da FUNDARTE. Montenegro, p.01-18, ano 21, no 46, setembro de 2021.

Disponível em: http://seer.fundarte.rs.gov.br/index.php/RevistadaFundarte/issue/archive $>30$ de setembro de 2021. 


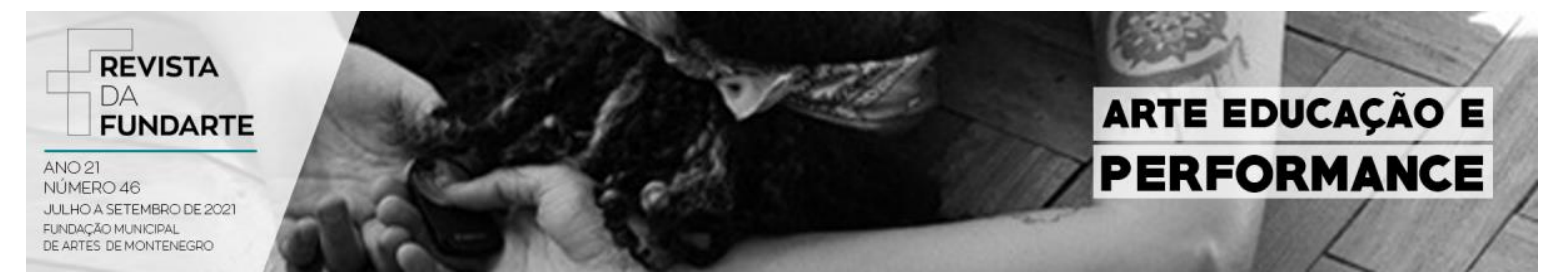

Esta criação de um corpo-signo organicamente amalgamado com o todo do espetáculo e deixando frestas imaginativas para o diálogo sensorial com o público foi o objetivo maior de PULSAÇÕES, na busca de um processo que contribuísse na experimentação de uma outra forma de abordagem sensível em todas as etapas de criação, na qual corpo, imagem e sensação fossem os vetores do acontecimento cênico.

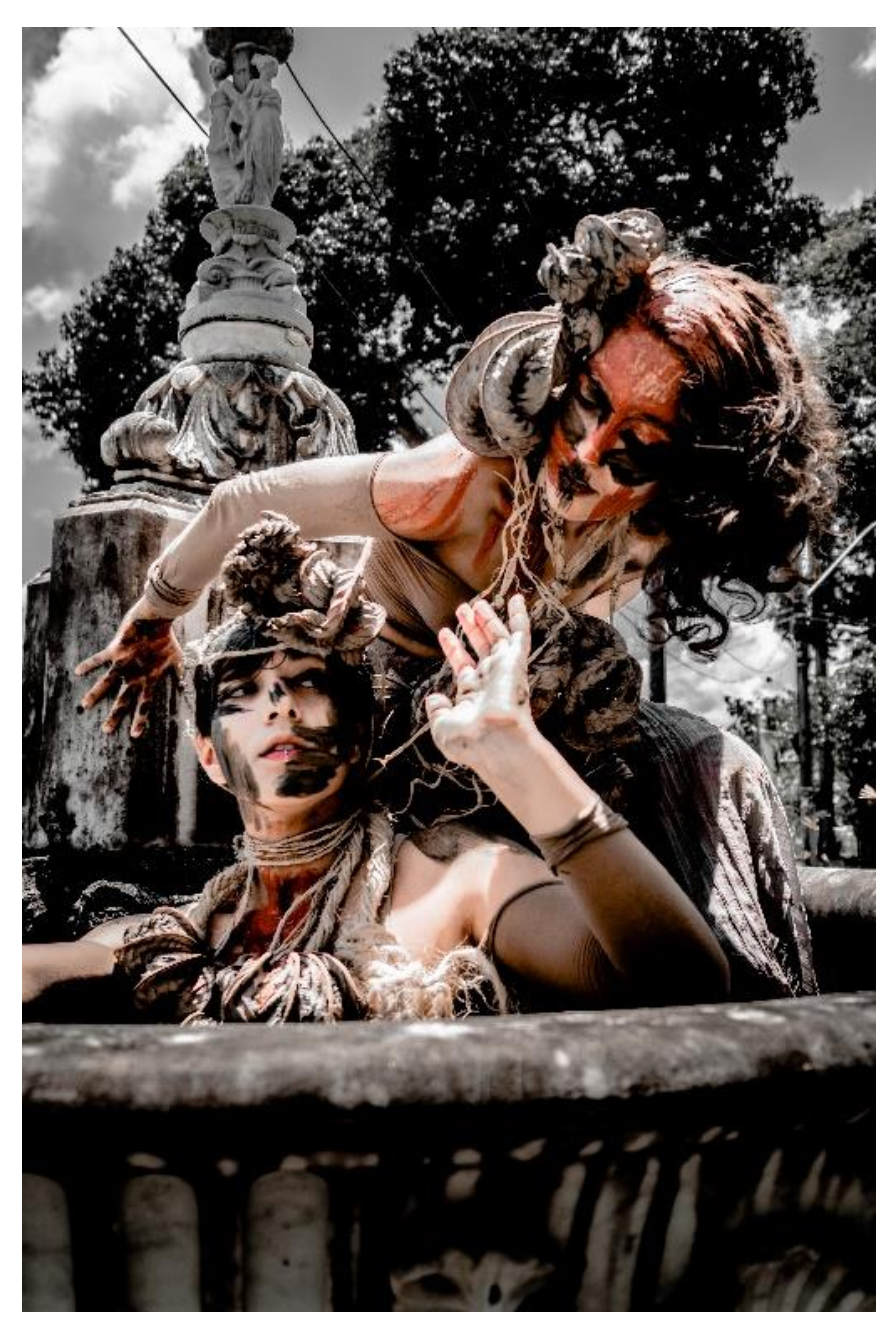

Giovana Boliveira e Rebeca de Oliveira Em experimento ao ar livre

(Passeio Público - Salvador - agosto/2019)

Foto: Gustoyle

OLIVEIRA, Erico José Souza de. PULSAÇÕES: processo entre corpo, imagem e sensação. Revista da FUNDARTE. Montenegro, p.01-18, ano 21, no 46, setembro de 2021.

Disponível em: http://seer.fundarte.rs.gov.br/index.php/RevistadaFundarte/issue/archive $>30$ de setembro de 2021. 


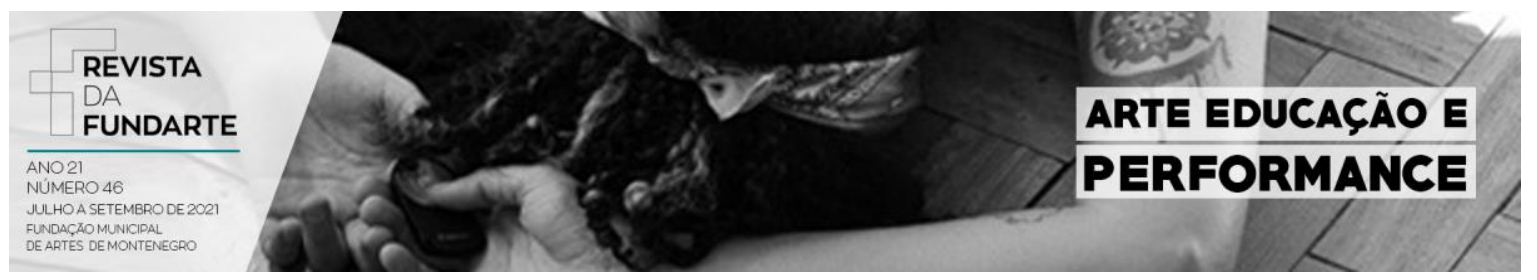

\section{Referências:}

ANDRADE, Welington. O teatro como lugar da subjetividade possível ou Os impasses da crítica diante da criação. Revista Sala Preta, São Paulo, Vol. 15, n. 2, p. 275-287, 2015.

AZEVEDO, Sônia Machado de. O papel do corpo no corpo do ator. São Paulo: Perspectiva, 2004.

BELLO, Denize Dall. A componente da teatralidade em Aby Warburg. 2016. 85 f. Dissertação (Mestrado em Estudos do Teatro) - Faculdade de Letras, Universidade de Lisboa, Lisboa, 2016.

CEZAR, Adieliton Tavares; JUCÁ-VASCONCELOS, Helena Pinheiro. Diferenciando sensações, sentimento e emoções: uma articulação com a abordagem gestáltica. Revista IGT na Rede, Rio de Janeiro, v. 13, no 24, 2016, p. 4-14. Disponível em http://www.igt.psc.br/ojs. Acesso em 17 de maio de 2020.

LISPECTOR, Clarice. (Título do livro). Rio de Janeiro: Editora Rocco, 1999.

LOBO, Lenora; NAVAS, Cássia. Teatro do Movimento: Um método para um intérprete criador. Brasília: LGE Editora, 2003.

MICHAELIS. Moderno dicionário da língua portuguesa. São Paulo: Companhia Melhoramentos, 1998.

OLIVEIRA, Erico José Souza de Oliveira. A roda do mundo gira: um olhar sobre a brincadeira do Cavalo Marinho Estrela de Ouro (Condado-PE). Recife: SESC, 2006.

OLIVEIRA, Erico José Souza de; LÍRIO, Vinícius da Silva. Teatralidades híbridas y elementos inmateriales en Esta propiedad está condenada de Tennessee Williams. Cuadernos de Música, Artes Visuales y Artes Escénicas, Bogotá, Vol. 10, N. 1, enero-jun. de 2015, pp. 153-165. (Referência do próprio autor)

PEDROSO, Júnia César. A percepção do corpo cênico em Klauss Vianna e Merleau-Ponty. In: IV REUNIÃO CIENTÍFICA DE PESQUISA E PÓS-GRADUAÇÃO EM ARTES CÊNICAS, v. 8, n. 1, 2007, Campinas. Anais da IV Reunião Científica de Pesquisa e Pós-Graduação em Artes Cênicas. Campinas: UNICAMP, 2007. Disponível em: https://www.publionline.iar.unicamp.br/index.php/abrace/issue/view/74. Acesso em 17 de maio de 2020.

OLIVEIRA, Erico José Souza de. PULSAÇÕES: processo entre corpo, imagem e sensação. Revista da FUNDARTE. Montenegro, p.01-18, ano 21, no 46, setembro de 2021.

Disponível em: http://seer.fundarte.rs.gov.br/index.php/RevistadaFundarte/issue/archive $>30$ de setembro de 2021. 


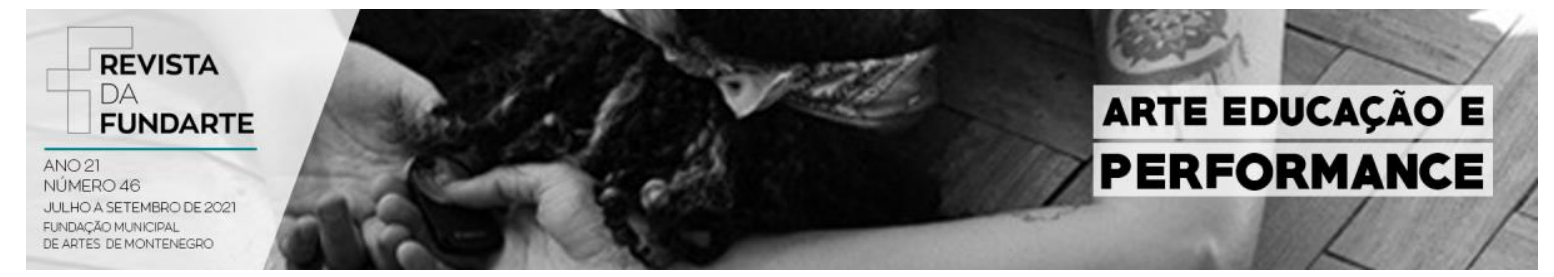

ROMAGNOLLI, Luciana Eastwood; MUNIZ, Mariana de Lima. Teatro como acontecimento convival: uma entrevista com Jorge Dubatti. Revista Urdimento, UDESC, Florianópolis, v.2, n. 23, 2014, p. 251-261.

STOBBAERTS, Georges. O corpo e a expressão teatral. Recife: CEPE, 2014. LES DEUX VOYAGES DE JACQUES LECOQ. Réalisation: Jean-Noël Roy e JeanGabriel Carasso. Avec: Jacques Lecoq, Ariane Mnouchkine et autres. Film de Jacques Lecoq, Jean-Gabriel Carasso, Jean-Claude Lallias, Jean-Noël Roy. Paris: On Line Productions, Anrat et Arte, 2006. 1 DVD (175min), color. Production On Line Produtions/CNPD, La Sept Arte, ANRAT.

OLIVEIRA, Erico José Souza de. PULSAÇÕES: processo entre corpo, imagem e sensação. Revista da FUNDARTE. Montenegro, p.01-18, ano 21, no 46, setembro de 2021.

Disponível em: http://seer.fundarte.rs.gov.br/index.php/RevistadaFundarte/issue/archive $>30$ de setembro de 2021. 